\title{
Modeling horizontal collaboration efficiency of several supply chains
}

\author{
Andrii Galkin ${ }^{1, *}$, Yevhen Kush ${ }^{1}$, Dmytro Roslavtsev ${ }^{1}$, Dmytro Prunenko ${ }^{1}$, and Oleksii \\ Lobashov $^{1}$ \\ ${ }^{1}$ O. M. Beketov National University of Urban Economy in Kharkiv, Department of Transport System \\ and Logistics, 61-002, Kharkiv,17, Marshala Baganova str
}

\begin{abstract}
.
Research background: Economic relations, which are formed under conditions of uncertainty and instability of the surrounding, require highly efficient techniques of engineering logistics activities. The high competitiveness on the logistics market forced to search new technologies that would give advantages over competitors. One of these advantages could be the decreasing of the transport service cost. The logistics activity, with the collaborative management of the complex of transport and logistics systems, is not well understood. The issues of the effectiveness of using various technologies in servicing a complex of logistics systems have not been sufficiently addressed. The effectiveness of horizontal collaboration of individual participants of various logistics systems to achieve common goals has not been fully studied. Lack of an unequivocal scientific justification and relevant practical developments determined the choice of the research topic and its relevance.

Purpose of the article: The aim of the paper is to identify patterns of influence of horizontal collaboration on efficiency of several supply chains.

Methods: The article used modelling of transportation process without horizontal collaboration - traditional one and with it. Invest indicators for assess collaborative and separated effectiveness of several supply chains were used.

Findings \& Value added: The use of horizontal collaboration technology leads to a synergistic effect: reducing the total number of vehicles required to service several supply chains; increased performance indicators. The patterns of the influence of technological parameters of the transport process on the effectiveness of horizontal transport collaboration are revealed.
\end{abstract}

Keywords: collaboration; horizontal; invest indicators; transport

JEL Classification: $R 40 ; R 42 ; R 41 ; C 81 ; C 6$

* Corresponding author: galkin.ts1@gmail.com 


\section{Introduction}

Constant aggravation of competition forces market participants to find ways to reduce the cost of goods and services while maintaining their quality and service level [1]. Logistics cost represents a significant share in the value of the goods [2]. One of the components of these costs is the costs associated with the delivery. The transportation costs depend on a wide range of indicators and conditions, in particular the strategy of transportation service: using own fleet (purchase), outsourcing, or a certain ratio of both [3]. The question of the formation of a fleet, its updating and maintenance, belongs to the range of issues of technical support of the logistics system. These issues do not misplace their relevance as they are crucial for the development and economic performance of the vehicle and logistics system [4].

\section{Methods}

Although the benefits of horizontal cooperation have been showed in the literature, available research does not provide a clear understanding of how this type of collaboration is created and used for sustainable transport and logistics. A systematic review of the literature [5] points to the creation of horizontal logistics alliances. This new form has the potential to promote and support the development of mechanisms that firms use to develop successful horizontal cooperation [6]. Logistics clusters can contribute to these mechanisms by providing better resource allocation, common culture, shared transport [7]. At the same time, it is unclear what mechanisms firms use to develop successful horizontal cooperation. Some conclusions on external horizontal cooperation provide useful insight into the features of horizontal cooperation in logistics [8], but very little has been achieved on the environmental implications of logistics cooperation [9]. The possibility of horizontal cooperation, through joint road transport services, leads to a change in approach to the pricing of transport services [10]. The analysis of methods for its calculation [11] showed that the existing scientific approaches do not sufficiently take into account technical andeconomic indicators in the conditions of road operating of several supply chains. Analysis of scientific and practical approaches to the transportation services of supply chains points to the diversity of technological schemes [12]. Existing approaches focus on processes where customer service is separate [13]. Simultaneously, mechanisms that would be forward-looking (5-7 years) and use the project analysis methodology as a tool for performance measurement and macro-analysis, with a wide range of technical variations is not enough consideration has been given to the economic parameters for their broad application in practice.

Other key factors in ensuring the reliability of supply chain services include the strategic importance of the outsourced ability (capacity) [14]. If the functional unit of a large organization is strategic, then to maintain key positions in the business, it must be maintained and developed separately. Under conditions of constant freight traffic [15], it is more efficient to use own road vehicle [16], in conditions of unevenness - hired vehicle [17]. Attracting additional road trucks can replace a separate group (business), both in whole and in part. In addition, an important factor in using own road trucks is to reduce the risk of failure in the absence of a vehicle. Here, first of all, the risks associated with the attraction of hired transport are important at the time the need for transportation arises. The ability to hire vehicles provides greater overall profits in the long run. It is not only about the loss of profit in any of the periods, but also about the impossibility of fulfilling the terms of delivery under the contract (Fig. 1). 


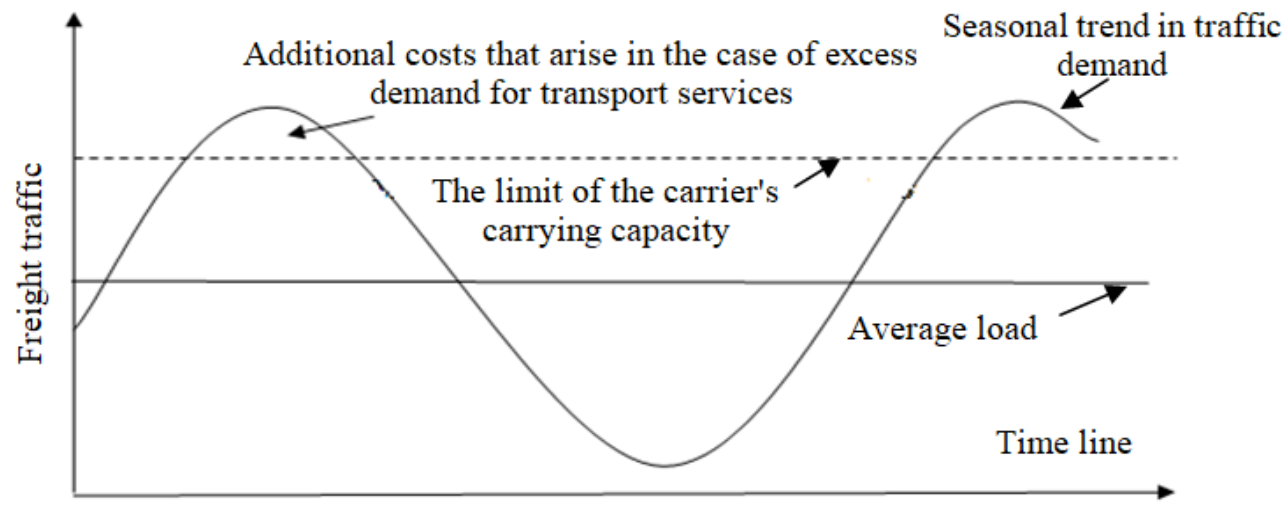

Fig. 1. The cycle of using the carrier's transportation capabilities

Analysis of the transport capabilities of logistics operators (Fig. 1) shows the occasional use of transport in certain periods of service. Seasonal changes in the parameters raises the question of the effectiveness of the use of own and hired road trucks and methods of their calculation. The analysis of modern methods of transport service of several logistics chains did not show the availability of methods for calculating the required number of hired and own road trucks under the conditions of horizontal collaboration technology. In addition, invest indicators patterns on transport process parameters are not set up.

The approach for assignment of own and hired vehicles for horizontal collaboration needs to be developed. Purpose of the article: The aim of the paper is to identify patterns of influence of horizontal collaboration on efficiency of several supply chains

\section{Results}

\subsection{Formation of a fleet of road vehicles based on the technology of horizontal collaboration}

Logistics operator is complex socio-technical system, consisting of a production system (means of production, human resources, information communication) and management systems. Logistics operator consists of different market segments, similar vehicle group which serve this segment, logistics service contracts and their commodities. The general scheme for evaluating effectiveness of horizontal collaboration has been proposed at fig. 2 . The possibility to collaborate transportation of different contracts over the long term allows redistributing road vehicle and finding their synergy amount number for service. The evaluating the effectiveness of such service can be estimate. The proposed model is suitable for recalculating number of commodities in the horizontal collaborating conditions.

Operating scenario have a certain structure: the formulation of the purpose; market analysis; analysis of technological options; production plan; organization plan; economic indicator calculation based on operating scenario. The transportation process is being core on the calculation of income and expenditure. 


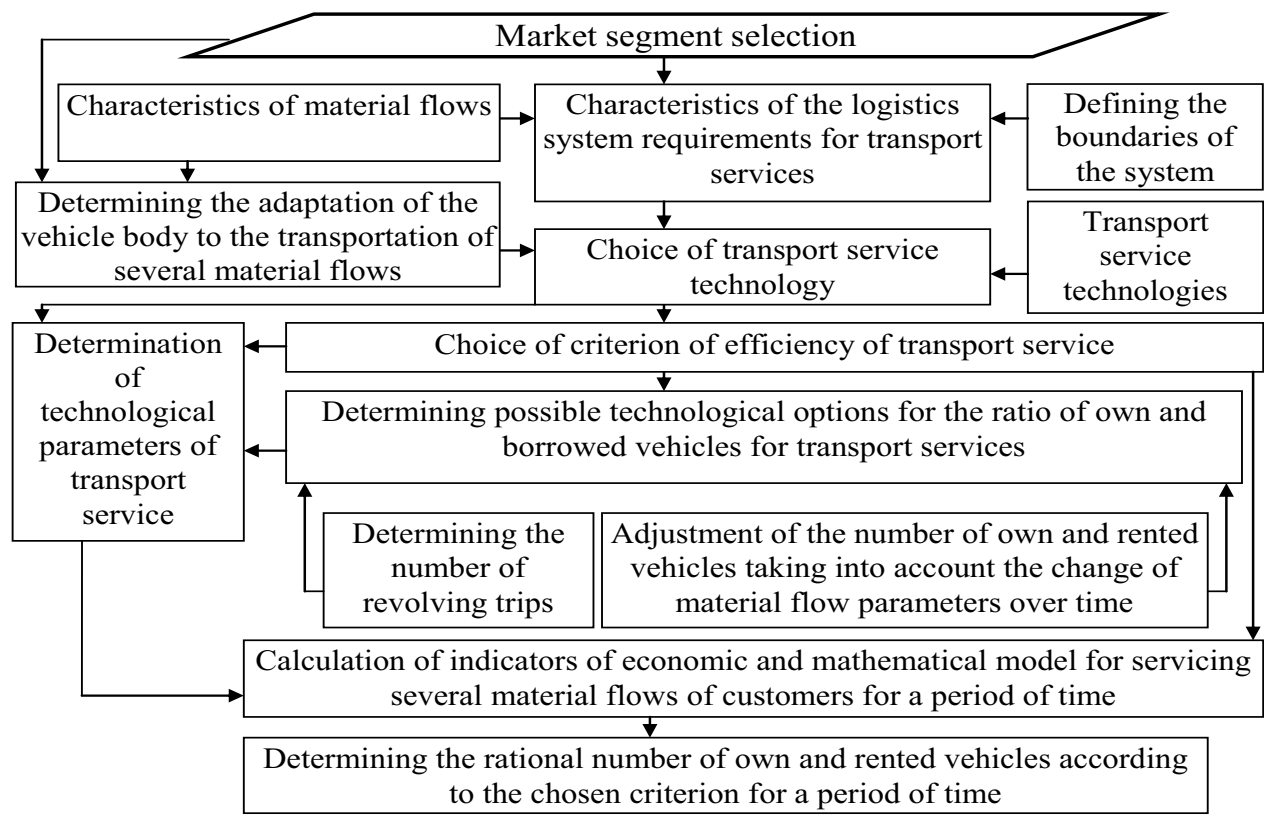

Fig. 2. Evaluating effectiveness of horizontal collaboration

In the long-term operating scenario with seasonal consumption of each commodity it is important to optimize the fleet capacity during the year. Different distribution of transportation orders in order to avoid seasonal underutilization of excess capacity or their lack. In this case, it is possible to redistribute unused vehicle between supply chains. But, different contracts have different values of order parameters: location of loading and unloading points, amount of deliveries by $t$ periods, etc. The possibility of using the similar type of goods when transporting a group of goods from different customers raises the question of separate or collaborative. Seasonal changes in the conditions of transport service of each $M$ commodity of the contract lead to changes in the required number of vehicles in periods. When they are determined for each individual customer, the maximum number of vehicles is selected for all service periods.

\subsection{Evaluating effectiveness of horizontal collaboration}

The efficiency evaluation project analysis method was developed in previous research has been used in this work [10]. Calculations of positive and negative flows have been according to these models according to designed technology of separate and horizontal collaboration operating scenario:

$$
\sum_{1}^{n} N P V_{T S_{-} n}^{\prime} \neq \sum_{1}^{n} N P V_{T S_{-} n}
$$

where $N P V_{T S_{-} n}-$ the NPV of the $n$-th systems when separate operating scenario, USD; $N P V_{T S_{-} n}^{\prime}$ - the NPV of the operating scenario of horizontal collaboration.

The estimation of separate and collaborating $N P V$ is different:

$$
N P V_{T S_{-} 1}+N P V_{T S_{-} 2}+\ldots .+N P V_{T S_{-} n}=\sum_{1}^{n} N P V_{T S_{-} n},
$$




$$
N P V_{T S_{-} 1}^{\prime}+N P V_{T S_{-} 2}^{\prime}+\ldots .+N P V_{T S_{-} n}^{\prime}=\sum_{1}^{n} N P V_{T S_{-} n}^{\prime},
$$

One of the results of progressive integration processes is the synergistic effect using horizontal collaboration technique:

$$
\sum_{1}^{n} N P V_{T S_{-} n}^{\prime} \geq \sum_{1}^{n} N P V_{T S_{-} n},
$$

Further, the value of the payback period is determined by the following formula:

$$
P P_{g}=a_{g}+b_{g} / c_{g}
$$

where

$P P_{g}$ - payback period for $g$-th operating scenario, years;

$a_{g}$ - number of time periods preceding the period in which there will be a full return on investments for $g$-th operating scenario;

$b_{g}$ - investment funds that remain unreturned at the beginning of the time period in which they will be fully refunded for $g$-th operating scenario;

$c_{g}$ - net benefits over a period of time in which there will be a full return on investments for $g$-th operating scenario.

\subsection{Results of simulations}

Field research shows, in case of an increase in demand for transportation and absence of own vehicles, logistics operators are faced with the need of hire vehicles. Based on the carried out calculations, the amount of vehicle to ensure all contractual obligations is 15 units (Fig. 3 and Fig.4).

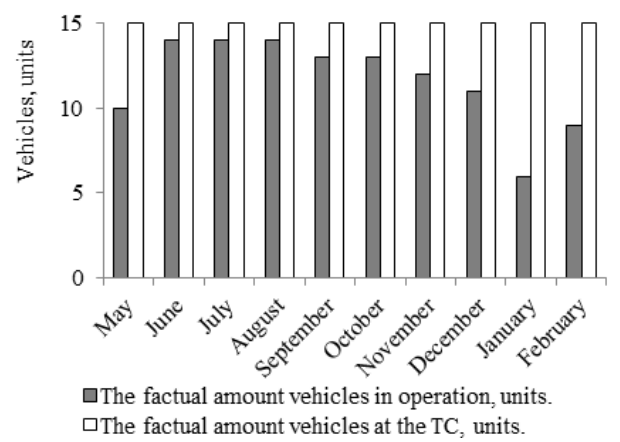

Fig. 3. Factual own vehicles amount variation

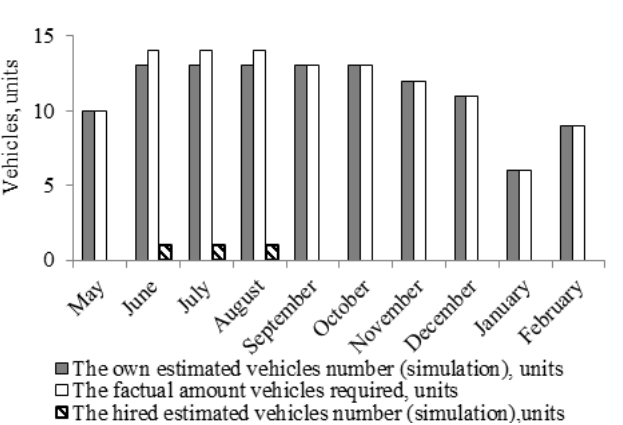

Fig. 4. The own and hired vehicles amount variation (simulating)

Conducted Simulations shows effect of different transportation options on efficiency of fleet usage fig.5-6.

The change in net present value on the mileage utilization ratio shows that an increase in the ratio increases the investment ratio. This is due to the income of the logistics operator, which depends on the amount of mileage with the cargo that is paid. When using the technology of horizontal collaboration in servicing logistic chains with an increase in the utilization rate of mileage, it is rational to use more own vehicles than hired ones, and with a decrease in the coefficient, vice versa. 
Analysis of the obtained patterns in Fig. 5 and 6 displays directly proportional patterns of the payback period from the mileage utilization factor. Analysis of patterns allows us to draw the following conclusions:

1. The payback period will decrease with increasing mileage utilization. With the same ratio of the number of own and hired road vehicles but under different operating scenarios, the payback period shows different efficiency results of the operating scenario.

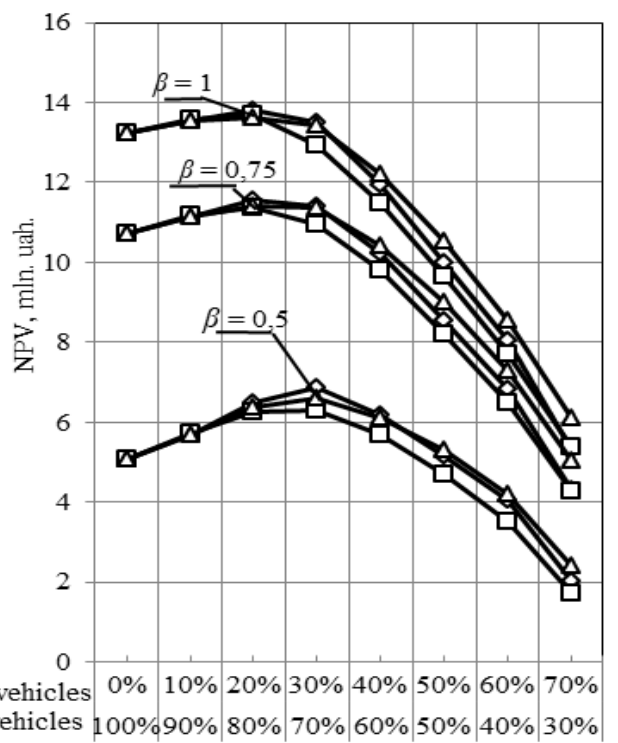

Ratio of own and hired vehicles

Fig. 5. Patterns of NPV on various operating scenarios of quantity and ratio of own/hired fleet for different route utilization rate of commodity:

$\longrightarrow$ - while transporting first commodity by hired vehicles; $-\square-$ - while transporting second commodity by hired vehicles; $\neg--$ while transporting third commodity by hired vehicles.

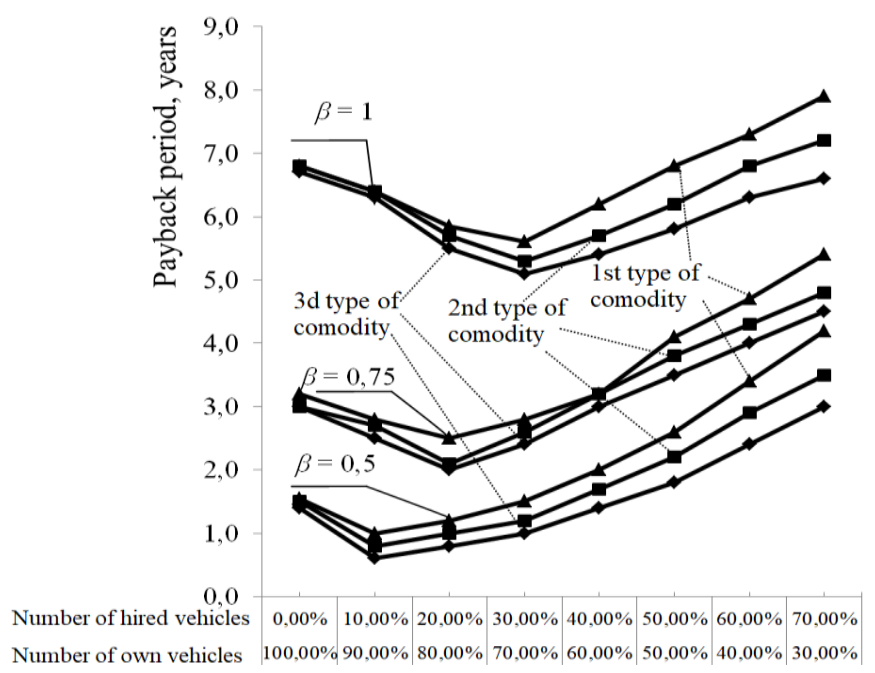

Ratio of own and hired vehicles

Fig. 6. Payback patterns of the number and ratio of own and hired vehicles in horizontal collaboration (at different mileage utilization rates): 
$\rightarrow-$ while transporting first commodity by hired vehicles; $\rightarrow-$ - while transporting second commodity by hired vehicles; $\longrightarrow$ - while transporting third MF by hired vehicles.

2. When implementing operating scenarios with a mileage utilization factor of 1 , it is rational to use an equal ratio of own and hired road vehicles. When the mileage utilization factor decreases, the rational number will increase and the number of hired vehicles will decrease according to Fig. 6.

3. Operating scenario efficiency results: NPV and payback period show the same results that do not contradict each other.

Analyzing fig 5 and 6, we can conclude that with increasing the number of hired road vehicles, the range of variation of efficiency indicators increases. This indicates ambiguity in the decision: which MF should be transported by own transport, and which by hired under the conditions of horizontal collaboration of logistics chains. Each operating scenario requires calculation to finally determine its effectiveness.

\section{Conclusions}

Based on a comprehensive analysis of modern research of science and practice on the functioning of the logistics management of a transport company, it was found that the role and place of joint transport services of several material flows in the overall system of logistics activities are not scientifically substantiated. It is advisable to improve the mechanisms and approaches to the determination of the indicators of the logistics activity of a road logistics operator when servicing several material flows.

The obtained patterns of change in the investment indicators of the logistics management model of the horizontal collaboration of several logistics chains made it possible to determine the influence of technical and operational parameters on the service technology. The technology of horizontal cooperation of transport and logistics systems has been developed, which would satisfy the requirements of the consumption system, ensure maximum profit of its participants and minimize the costs of freight transportation. The use of the proposed technology of horizontal collaboration of supply chains will allow ensuring the efficiency of the use of road vehicles, to increase the competitiveness of logistics operator, to reduce costs and to determine the long-term efficiency of investments.

The use of horizontal collaboration technology leads to a synergistic effect: reducing the total number of vehicles required to service several logistics systems; increased performance indicators - KPI, and more. The functioning of the transport intermediary in the horizontal collaboration of several logistics chains is investigated. A technological model of transport service of several logistics chains with its own parameters is developed. The patterns of the influence of technological parameters of the transport process on the effectiveness of horizontal transport collaboration are revealed.

\section{References}

1. Galkin, A., Dolia, C., Davidich, N. (2017). The role of consumers in logistics systems. Transportation Research Procedia, 27, 1187-1194.

2. Galkin, A., Kush, Ye., Davidich, N., Davidich, Y. (2019) Evaluation of influence of the logistics chain infrastructure on the logistics costs formation. 15th Scientific and practical international conference International transport infrastructure, industrial centers and corporate logistics - NTI-UkrSURT 2019, vol. 67 (pp. 1-6). EDP Sciences.

3. Galkin, A., Kumar, C., Roslavtsev, D., Lobashov, O., Schlosser, T. (2020). Influence Parameters of Transportation Process on Own/Hired Fleet Selection. Transportation Research Procedia, 48, 1815-1823. 
4. Makarova, I., Shubenkova, K., Pashkevich, A. (2017). Logistical costs minimization for delivery of shot lots by using logistical information systems. Procedia Engineering, $178,330-339$.

5. Brekalo L., Albers S. (2016) Effective logistics alliance design and management. International Journal of Physical Distribution \& Logistics Management, 46(2), 212240.

6. Rivera, L., Gligor, D., Sheffi, Y. (2016). The benefits of logistics clustering. International Journal of Physical Distribution \& Logistics Management, 46(3), $242-$ 268.

7. Bolumole, Y. A., Closs, D. J., Rodammer, F. A. (2015). The economic development role of regional logistics hubs: a cross- country study of interorganizational governance models. Journal of Business Logistics, 36(2), 182-198.

8. Martin, N., Verdonck, L., Caris, A., Depaire, B. (2018) Horizontal collaboration in logistics: decision framework and typology. Operations Management Research, 11(12), 32-50

9. Van Lier, T., Caris, A., Macharis, C. (2016) Sustainability SI: Bundling of outbound freight flows: Analyzing the potential of internal horizontal collaboration to improve sustainability. Networks and Spatial Economics, 16(1), 277-302.

10. Halkin, A., Skrypin, V., Kush, E., Vakulenko, K., Dolia, V. (2017). Invest Approach to the Transportation Services Cost Formation. Procedia Engineering, 178, 435-442.

11. Pan, S. (2017). Horizontal Collaboration for Sustainable Transport and Logistics (Doctoral dissertation).

12. Wang, Y., Yuan, YY., Guan, XY., Wang, HZ., Liu, Y., Xu, MZ. (2019). Collaborative Mechanism for Pickup and Delivery Problems with Heterogeneous Vehicles Under Time Windows. Sustainability, 11(12), 3492.

13. Sheffi, Y., Saenz, M. J., Rivera, L., Gligor, D. (2019). New forms of partnership: the role of logistics clusters in facilitating horizontal collaboration mechanisms. European Planning Studies, 27(5), 905-931.

14. Rai, H. B., Verlinde, S., Macharis, C., Schoutteet, P., Vanhaverbeke, L. (2019). Logistics outsourcing in omnichannel retail. International Journal of Physical Distribution \& Logistics Management, 49(3), 167-286.

15. Galkin, A., Dolia, C., Davidich, N. (2017). The role of consumers in logistics systems. Transportation Research Procedia, 27, 1187-1194.

16. Olkhova, M., Davidich, Y., Roslavtsev, D., Davidich, N. (2017). The efficiency of transportating perishable goods by road and rail. Transport Problems, 12(4), 37-50.

17. Galkin, A., Obolentseva, L., Balandina, I., Kush, E., Karpenko, V., Bajdor, P. (2019). Last-Mile Delivery for Consumer Driven Logistics. Transportation Research Procedia, 39, 74-83. 